\title{
ELISA INDIRETO NA DETECÇÃO DE Salmonella spp. EM LINGÜIÇA SUÍNA ${ }^{1}$
}

\author{
AN INDIRECT ELISA FOR DETECTION OF Salmonella spp. \\ IN SWINE SAUSAGE
}

\section{Andrea Pinto Loguercio² ${ }^{2}$ José Antonio Guimarães Aleixo ${ }^{3}$ Agueda Castagna de Vargas ${ }^{4}$ Mateus Matiuzzi da Costa $^{5}$}

\section{RESUMO}

Um teste ELISA, baseado em um anticorpo monoclonal $(M A b)$ específico para uma proteína de membrana externa de Salmonella enterica serovar Enteritidis foi comparado com o método de cultivo tradicional na detecção de Salmonella spp. em 110 amostras de lingüiça suína frescal. A prevalência do patógeno nas amostras foi de $11,82 \%$ de acordo com o cultivo tradicional. O teste ELISA revelou sensibilidade, especificidade, valores preditivos positivos e negativos de $100 \%$, $98 \%, 87 \%$ e $100 \%$, respectivamente. Tais achados indicam que, comparado ao sistema tradicional, o teste imunológico foi bastante eficaz na determinação de Salmonella spp. em amostras de lingüiças naturalmente contaminadas.

Palavras-chave: Salmonella, ELISA, lingüiça suína.

\section{SUMMARY}

The performance of an ELISA test based on a monoclonal antibody (MAb) specific to Salmonella enterica serovar Enteritidis was compared with standard culture method for detection of Salmonella spp. in 110 samples of swine fresh sausages. The prevalence was of $11.82 \%$, according the standard method. Comparison of ELISA and the culture method revealed the sensitivity, specificity, and positive and negative predictive values of $100 \%, 98 \%, 87 \%$ and $100 \%$, respectively. Results indicate that compared with standard culture method the ELISA test was effective in detection of Salmonella in swine sausages naturally contaminated.

Key words: Salmonella, ELISA, swine sausage.

\section{INTRODUÇÃO}

O impacto social e econômico das toxinfecções alimentares é considerável e a salmonelose representa um papel importante neste fenômeno. Existem poucos dados acerca da participação dos alimentos de origem animal na epidemiologia de salmonelose humana nos países em desenvolvimento, contrastando com os países desenvolvidos onde eficientes pesquisas etiológicas são realizadas (LÁZARO et al., 1997).

A incidência real de salmonelas nas toxinfecções alimentares é desconhecida, uma vez que, freqüentemente pequenos surtos não são relatados para as autoridades de Saúde Pública. Sabe-se, no entanto, que o número de casos de salmonelose tem aumentado anualmente nos Estados Unidos (BEAN \& GRIFFIN, 1990), Holanda (SIMONE et al., 1997), Itália (FANTASIA \& FILETICI, 1994) e República Checa (OMS, 1998). CHALKER \& BLASER (1988) fazendo um estudo do número de infecções por salmonelas através de três métodos diferentes, estimaram que, somente nos Estados Unidos, devem ocorrer, a cada ano, entre 800 mil e 3 milhões e 700 mil casos humanos.

Para pesquisa de Salmonella spp. em alimentos, o método recomendado pelo

\footnotetext{
${ }^{1}$ Parte da Dissertação de Mestrado em Ciência e Tecnologia Agroindustrial apresentada pelo primeiro autor à Universidade Federal de Pelotas (UFPel).

${ }^{2}$ Engenheiro Agrônomo MSc., Doutoranda Programa de Pós-graduação em Agronomia, Universidade Federal de Santa Maria (UFSM).

${ }^{3}$ Médico Veterinário, PhD, Professor Adjunto, Centro de Biotecnologia, UFPel, Campus Universitário, 96019-900 Capão do Leão - RS.

E-mail: biotjaga@ufpel.tche.br.

${ }^{4}$ Médico Veterinário, Doutor, Professor Assistente do Departamento de Medicina Veterinária Preventiva da UFSM.

${ }^{5}$ Médico Veterinário, Mestrando do Programa de Pós-graduação em Biotecnologia, Universidade Federal do Rio Grande do Sul.
} 
Bacteriological Analytical Manual (BAM), American Public Health Association (APHA), Associação Brasileira de Normas Técnicas (ABNT) e Ministério da Agricultura Pecuária e Abastecimento (MAPA) é o método clássico de cultivo, desenvolvido com a finalidade de garantir a detecção deste microrganismo, mesmo em alimentos que apresentem situações extremamente desfavoráveis para o seu desenvolvimento, como alimentos com microbiota competidora muito maior que a população de Salmonella spp., alimentos em que as células se encontrem em número muito reduzido e/ou alimentos em que as células se encontrem injuriadas pela técnica de preservação, como a aplicação de calor, congelamento, secagem, salga, cura, entre outros (ECKNER et al., 1992). O isolamento clássico de Salmonella spp. pode ser dividido em quatro etapas: pré-enriquecimento, enriquecimento em caldo seletivo, plaqueamento seletivo diferencial e confirmação. A seleção dos meios de cultura e metodologia de preparo e cultivo das amostras varia de acordo com a fonte consultada, visando sempre, no entanto, obter as melhores condições de isolamento frente aos diferentes tipos de amostras (HAJDENWURCEL, 1997).

O pré-enriquecimento objetiva recuperar as células de Salmonella spp. que, normalmente, estão presentes em pequenas quantidades e em condições debilitadas nos alimentos processados. $\mathrm{O}$ enriquecimento em caldo seletivo objetiva inibir a multiplicação da microbiota acompanhante e promover a elevação preferencial do número de células de salmonela, incubando-se a amostra préenriquecida em caldo seletivo por 18 a 24 horas. Nesta etapa, recomenda-se a utilização de dois diferentes meios, pois a resistência da Salmonella spp. aos agentes seletivos varia de cepa para cepa. O plaqueamento seletivo diferencial visa promover o desenvolvimento preferencial de colônias de Salmonella spp., com características típicas que as distingam dos competidores, para posterior confirmação bioquímica e sorológica. Na etapa de enriquecimento, recomenda-se a utilização de, pelo menos, dois meios distintos para o plaqueamento. Mediante provas bioquímicas e sorológicas pode-se confirmar se os isolados típicos obtidos nas placas são realmente de Salmonella (JAY, 1988). Portanto, os procedimentos de cultivo padrão para o isolamento de Salmonella $e \mathrm{~m}$ alimentos são trabalhosos e requerem um mínimo de 4 dias para se obterem evidências presuntivas de contaminação (D'AOUST et al., 1990).

A necessidade de métodos mais rápidos $\mathrm{e}$ menos laboriosos de detecção tem levado a avanços significativos no desenvolvimento de pesquisa e comercialização de "kits" de diagnóstico baseados em técnicas sorológicas, imunoabsorbância enzimática, hibridização de ácido nucléicos, entre outras (D'AOUST et al., 1993). Vários "kits" comerciais de diagnóstico baseados na técnica Enzyme-Linked Immunoabsorbent Assay (ELISA) estão disponíveis no mercado. Embora estudos comparativos tenham estabelecido sua equivalência com o método padrão de cultivo, é necessário validar a semelhança de sensibilidade entre ambas as metodologias (D'AOUST et al., 1992).

A importância e precisão da utilização de ensaios imunológicos para fins de diagnóstico está na diversidade de anticorpos formados para um mesmo antígeno e que podem ser escolhidos, no caso dos anticorpos monoclonais. Esta diferenciação ocorre devido aos vários tipos de imunoglobulinas formadas (HARLOW \& LANE, 1988). A tecnologia de produção de anticorpos monoclonais baseia-se na fusão de células de mieloma com células de baço de um animal imunizado, provendo assim, hibridomas capazes de crescerem indefinidamente em meio de cultura com a capacidade de produção de anticorpos, os quais uma vez clonados, apresentam-se altamente específicos (DUARTE \& PRADO FILHO, 1998). Em ciência de alimentos, a tecnologia de produção de anticorpos monoclonais vem sendo utilizada com o propósito de detectar microrganismos contaminantes em alimentos. Uma aplicação bastante importante desta tecnologia é a detecção de contaminantes bacterianos (DUARTE, 1996).

O primeiro imunoensaio para Salmonella spp. foi realizado em 1977 e, desde então, vários ELISA têm sido desenvolvidos, usando-se tanto anticorpos policlonais como monoclonais para detectar a maioria dos sorovares de Salmonella spp. Com o desenvolvimento da tecnologia de produção de anticorpos monoclonais, trabalhos utilizando essa metodologia surgiram mostrando uma maior sensibilidade na detecção deste microrganismo. Nove anticorpos monoclonais capazes de detectar Salmonella spp. viva em alimentos foram produzidos posteriormente (TORENSMA et $\boldsymbol{a l}$., 1992). Estes anticorpos reagiram contra Salmonella spp. pertencente aos sorogrupos A, B, C1, C2, D, E e K, e contra $S$. choleraensuis subsp. diarizonae. Não houve significância nas reações cruzadas com outras bactérias.

Dois "kits" comerciais receberam o "status" de oficiais pela AOAC (Association of Official Analytical Chemists), desde 1989. Em comparação com o método convencional, o tempo total é reduzido em 2 dias e a análise estatística dos dados não tem indicado diferenças significativas 
porém, o principal problema relatado por todos os métodos, que não o convencional, é o aparecimento de resultados falso-positivos e/ ou falso-negativos (BEUMER et al., 1991). De acordo com os mesmos autores, resultados falso-negativos no teste ELISA podem ser eliminados utilizando-se um anticorpo monoclonal de alta especificidade.

TAPCHAISRI et al. (1999), em um ensaio tipo dot-ELISA, utilizando-se de um MAb específico para Salmonella spp. encontraram sensibilidade igual a 93,33\%, especificidade de $91,76 \%$ e eficácia de $92 \%$ quando comparado ao método de cultivo tradicional em 100 amostras de carne suína disponíveis no mercado de varejo sob diferentes formas. BAAY \& VELD (1993) utilizaram como antígeno a porção lipopolissacarídica da bactéria (antígenos tipo O) na obtenção de soros policlonais para detecção deste microrganismo em frangos e ovos, a fim de diminuir a reação cruzada que ocorria em um ELISA contra S. enteritidis.

O objetivo deste trabalho foi avaliar um sistema ELISA baseado em um anticorpo monoclonal que reage especificamente com uma proteína de membrana externa de Salmonella dos sorogrupos A, B, C, D e E, para a determinação de Salmonella spp. em lingüiça suína.

\section{MATERIAL E MÉTODOS}

Cento e dez amostras de lingüiça frescal suína refrigerada, pesando cerca de 150 gramas cada, foram adquiridas ao acaso, no comércio varejista de Pelotas e Santa Maria, RS. As amostras foram transportadas ao laboratório em caixa de material isotérmico contendo gelo reciclável e conservadas em geladeira até o momento das análises. O tempo decorrido entre a coleta das amostras e o início das análises nunca ultrapassou duas horas. $\mathrm{Na}$ metodologia tradicional de cultivo, foi empregada a técnica de pré-enriquecimento em Caldo Lactosado, com incubação a $37^{\circ} \mathrm{C}$ por 24 horas e enriquecimento seletivo nos caldos tetrationato- verde brilhante e Rappaport-Vassiliadis, incubados a $42^{\circ} \mathrm{C}$ por 24 horas. Para o isolamento de colônias, foi realizada a semeadura em superfície em Ágar Hektoen e Ágar XLD, com incubação a $37^{\circ} \mathrm{C}$ por 24 horas, segundo HAJDENWURCEL (1997). As colônias com reações típicas de Salmonella spp. foram submetidas aos testes bioquímicos de TSI, LIA e uréia e aquelas que apresentavam comportamento bioquímico de salmonelas foram submetidas, então, à prova de soroaglutinação, empregando-se soros polivalentes somático e flagelar para confirmação final. Foram retirados 0,5m $\ell$ do caldo de enriquecimento Rappaport Vassiliadis para inoculação e cultivo em $15 \mathrm{~m} \ell$ de Caldo BHI, durante um período de 6 horas a $37^{\circ} \mathrm{C}$ sob agitação. Após este período, realizou-se a termoextração de antígenos mantendo-se o cultivo em banho-maria a $100^{\circ} \mathrm{C}$ por 15 minutos. Após o esfriamento, os tubos foram estocados congelados ($20^{\circ} \mathrm{C}$ ) até a reação do ELISA.

Após o descongelamento das amostras em BHI, realizou-se a sensibilização das micro- placas de ELISA com $50 \mu \ell$ de antígeno termoextraído em cada compartimento, sendo utilizados, para cada amostra, 3 poços. Neste momento, fez-se também a sensibilização dos poços destinados ao controle positivo e negativo com extrato puro de Salmonella enteritidis ATCC 13076, tratado termicamente e ajustado à absorbância 1,000 por espectrofotometria e com uma mistura de cultivos negativos para Salmonella spp., respectivamente. As placas foram incubadas em estufa a $37^{\circ} \mathrm{C}$ por 1 hora e 30 minutos. Após este tempo, eliminou-se o volume restante e procedeu-se a lavagem das mesmas com solução tamponada detergente de $\mathrm{pH}$ neutro $(\mathrm{NaC} \ell-8,0 \%$; $\mathrm{KH}_{2} \mathrm{PO}_{4}-0,2 \% ; \mathrm{Na}_{2} \mathrm{HPO}_{4}$ anidro- $1,15 \%$; $\mathrm{KC} \ell-$ $0,2 \%$; Timerosal $0,2 \% \mathrm{p} / \mathrm{v}$ ), sendo o procedimento de lavagem repetido por 3 vezes. Após, foram colocados $50 \mu \ell$ do anticorpo $424 \mathrm{H}$, que é um anticorpo não comercial produzido no Centro de Biotecnologia da UFPel, previamente diluído em solução tamponada neutra (PBS - 1:1000). O anticorpo foi colocado em dois dos três poços de cada amostra, de modo que permitisse se obter dois poços positivos (antígeno + anticorpo) e um negativo (somente antígeno) para cada amostra. As placas foram incubadas a $37^{\circ} \mathrm{C}$ por uma hora. Após três lavagens com tampão neutro, adicinou-se o conjugado. O conjugado utilizado foi Proteína A Peroxidase diluído na mesma solução tamponada detergente neutro (1:2000). Alíquotas de 50 $\mu$ f foram adicionadas a cada poço, reservando-se um poço para controle do conjugado (conjugado + substrato). As placas foram novamente incubadas a $37^{\circ} \mathrm{C}$ por uma 1 hora e 30 minutos e, passado este tempo, foram realizadas cinco lavagens com o tampão detergente neutro. Utilizou-se como substrato cromógeno uma solução de OPD, tampão ácido (ácido cítrico - 1,48\%; $\mathrm{Na}_{2} \mathrm{HPO}_{4}$ anidro - 1,37\%; $\mathrm{pH} 4,0)$ e peróxido de hidrogênio. Em cada poço, adicionaram-se $50 \mu \ell$ de substrato, reservando-se um poço para controle do substrato. As placas foram mantidas no escuro por 15 minutos e depois levadas ao leitor de ELISA com comprimento de onda de $450 \mathrm{~nm}$

Ciência Rural, v. 32, n. 6, 2002. 


\section{RESULTADOS E DISCUSSÃO}

A prevalência de Salmonella spp. identificada pelo método convencional foi de $11,82 \%$ e de $13,64 \%$ através do teste ELISA. Os valores encontrados encontram-se dentro da amplitude apresentada por outros trabalhos similares no Brasil, sendo inferiores aos achados de FUZIHARA \& FRANCO (1993), que encontraram $33 \%$ de amostras contaminadas, em produtos de carne suína em Santo André, SP, e aos de REIS et al. (1995), que detectaram Salmonella spp. em $35,3 \%$ das amostras de lingüiça frescal pesquisadas em Cuiabá, MT. No entanto, SABIONI et al. (1999) relataram a ocorrência de Salmonella spp. em 3\% das amostras de lingüiça suína avaliadas em Ouro Preto, MG, e NOGUEIRA PINTO et al. (1999) detectaram o patógeno em $10 \%$ das amostras de embutidos suínos em Botucatu, SP. Não existem, no Brasil, dados estatísticos sobre o grau de contaminação dos produtos cárneos por salmonelas. Entretanto, conforme os valores acima apresentados, há um total desacordo com os padrões da legislação vigente (BRASIL, 1997), que é de ausência de Salmonella spp. em 25g do produto, denotando, portanto, a necessidade de maiores cuidados na vigilância e nas práticas de manufatura de tais produtos a fim de diminuir os riscos aos potenciais consumidores.

Os resultados comparativos entre o teste ELISA e a metodologia convencional estão apresentados na tabela 1. A fim de calcular a

Tabela 1 - Resultados comparativos entre a metodologia convencional e o ELISA na pesquisa de Salmonella spp. em lingüiças suínas tipofrescal.

\begin{tabular}{|c|c|c|c|}
\hline \multirow{2}{*}{ ELISA } & \multicolumn{2}{|c|}{ Metodologia convencional } & \multirow{2}{*}{ Total } \\
\hline & Positivo & Negativo & \\
\hline Positivo & 13 & 2 & 15 \\
\hline Negativo & 0 & 95 & 95 \\
\hline Total & 13 & 97 & 110 \\
\hline \multicolumn{2}{|c|}{ PARÂMETRO } & \multicolumn{2}{|c|}{ VALOR PERCENTUAL (\%) } \\
\hline \multicolumn{2}{|c|}{ Sensibilidade $^{\text {a }}$} & \multicolumn{2}{|c|}{100} \\
\hline \multicolumn{2}{|c|}{ Especificidade $^{b}$} & \multicolumn{2}{|c|}{98} \\
\hline \multicolumn{2}{|c|}{ Valor Preditivo Positivo $^{c}$} & \multicolumn{2}{|c|}{87} \\
\hline \multicolumn{2}{|c|}{ Valor Preditivo Negativo ${ }^{\mathrm{d}}$} & \multicolumn{2}{|c|}{100} \\
\hline
\end{tabular}

a Sensibilidade $=$ Amostras positivas em ambos os testes $/$ Total de amostras positivas no teste convencional $\times 100=$ $13 / 13 \times 100=100$

${ }^{\mathrm{b}}$ Especificidade $=$ Amostras negativas no ELISA / Total de amostras negativas $\times 100=95 / 97 \times 100=97,94$

${ }^{\mathrm{c}}$ VPP $=$ Amostras positivas nos dois testes / Total de amostras positivas no ELISA x $100=13 / 15 \times 100=86,67$

${ }^{\mathrm{d}} \mathrm{VPN}=$ Amostras negativas nos dois testes $/$ Total de amostras negativas no ELISA x $100=95 / 95 \times 100=100$ eficácia do teste ELISA foi estabelecido como ponto de corte entre os resultados positivos e negativos neste teste, um valor de densidade ótica (DO) de 0,373 representando a média da DO das amostras negativas mais dois desvios-padrões. Das 110 amostras analisadas, 13 apresentaram-se contaminadas por Salmonella spp. de acordo com a metodologia convencional e 15 de acordo com o imunoensaio, havendo portanto 2 resultados "falsopositivos". Em ambas as amostras, onde Salmonella spp. foi detectada pelo ELISA mas não pelo cultivo tradicional, as amostras apresentavam problemas de crescimento excessivo no plaqueamento seletivo, provavelmente com espécies de Proteus spp., pois a distinção foi feita pelo teste bioquímico da urease. JAY \& COMAR (1988) relataram problema semelhante ao compararem o cultivo tradicional com o kit TECRA EIA ${ }^{\circledR}$.

Na tabela 2, são mostrados os resultados da análise de 110 amostras de lingüiça suína frescal pela metodologia convencional e ELISA. Nenhuma das 13 amostras positivas no método tradicional apresentou resultado negativo no ELISA, não ocorrendo, portanto, "falsos- negativos". Este fato demonstra a eficácia do anticorpo, sob as condições do teste, na determinação do patógeno, pois ele foi capaz de detectar o patógeno mesmo naquelas amostras onde a metodologia convencional foi falha.

O ELISA, quando comparado ao cultivo tradicional, apresentou sensibilidade de $100 \%$, especificidade de $98 \%$, Valor Preditivo Positivo (VPP) de $87 \%$ e Valor Preditivo Negativo (VPN) de $100 \%$, conforme dados apresentados na tabela 1 . Tais valores são bastante semelhantes aos encontrados por TAPCHAISRI $\boldsymbol{e}$ t al. (1999), que trabalhando com um anticorpo monoclonal (MAb) gênero específico em um dot-ELISA em amostras de alimentos, obteve sensibilidade de 93,33\%, especificidade de $91,76 \%$, VPP de $66,66 \%$ e VPN igual a 98,73\%. REIS et al. (1999), trabalhando com a padronização de um teste imunoenzimático para detecção de Salmonella em alimentos, encontraram valores de especificidade e sensibilidade de 87 e $100 \%$, respectivamente. McDONOUGH et al. (1998), em trabalho com dois antígenos específicos em amostras de frangos, encontraram valores variando entre 94 e $62 \%$ para sensibilidade e entre 55 e $75 \%$ para especificidade em um teste ELISA automatizado. Por outro lado, HANAI et al. (1997), ao compararem seis "kits" comerciais com o método tradicional na detecção de Salmonella spp. em alimentos, encontram sensibilidades variando entre 29 (amostras naturalmente contaminadas) e 100\% (sorovares) nos "kits" tipo ELISA. 
Tabela 2 - Detecção de Salmonella spp. em lingüiça suína frescal pelo método convencional e ELISA.

\begin{tabular}{ccc}
\hline Amostra & Método convencional & ELISA $(\mathrm{DO})^{\mathrm{a}}$ \\
\hline 09 & + & 0,796 \\
13 & + & 0,676 \\
17 & + & 0,803 \\
80 & + & 0,800 \\
84 & + & 0,780 \\
85 & - & 0,644 \\
87 & + & 0,696 \\
90 & + & 0,690 \\
93 & + & 0,732 \\
96 & + & 0,632 \\
99 & + & 0,732 \\
104 & + & 0,753 \\
106 & + & 0,686 \\
107 & - & 0,664 \\
108 & + & 0,757 \\
Demais amostras & - & $0,373^{\mathrm{b}}$ \\
\hline
\end{tabular}

a - Densidade Ótica a 450nm

b - média das DO das amostras negativas \pm dois desvios-padrões

Diferentes tipos de testes ELISA foram desenvolvidos por THORNS et al. (1996) a fim de detectar infecções por $\boldsymbol{S}$. enteritidis em aves. A sensibilidade dos testes apresentou uma amplitude de 5 a $100 \%$. Os dados obtidos neste experimento demonstram que o teste ELISA apresenta vantagens em comparação ao método tradicional. No entanto, por ser baseado em um anticorpo monoclonal preparado contra Salmonella enteritidis e que reage também com outras salmonelas dos principais sorovares isolados em alimentos, pode apresentar resultados negativos no caso do sorovar presente na amostra ser diferente dos sorovares reagentes. Neste experimento, houve uma concordância muito grande entre os resultados do cultivo tradicional e do ELISA, demonstrado pelo baixo número de "falsospositivos" e inexistência de "falsos-negativos", indicando que o anticorpo utilizado (424 H) apresentou-se bastante eficaz na detecção deste microrganismo em amostras de lingüiça suína naturalmente contaminadas.

\section{CONCLUSÃO}

O teste ELISA apresentou uma correlação de resultados muito grande em relação à metodologia convencional de detecção e isolamento de Salmonella spp. em alimentos, com a vantagem de ser mais rápido e de alta sensibilidade, diminuindo o tempo do resultado de 4 para 2 dias. Para uma nova técnica ser aceita e utilizada com confiança é necessário que seja pelo menos tão boa ou superior ao método anterior. $\mathrm{O}$ ensaio imunológico aqui descrito parece satisfazer este requerimento, portanto, oferece a possibilidade de ser utilizado em amostras naturalmente contaminadas, sendo necessário fazer a validação estatística e avaliação por um Laboratório Oficial de Referência.

\section{REFERÊNCIAS BIBLIOGRÁFICAS}

BAAY, M.F.D., VELD, J.H.J. Alternative antigens reduce crossreactions in an ELISA for the detection of Salmonella enteritidis in poultry. J Appl Bacteriol, v.74, p.243-247, 1993.

BEAN, N.H., GRIFFIN, P.M. Foodborne disease outbreaks in the United States, 1973-1987: Pathogens, vehicles and trends. J Food Prot, v.53, n.9, p.804-817, 1990.

BEUMER, R.R., BRINKMAN, E., ROMBOUTS, F.M. EnzymeLinked immunoassays for the detection of Salmonella spp.: a comparison with other methods. Int J Food Microbiol, v.12, p.363-374, 1991.

BRASIL. Ministério da saúde. Secretaria Nacional de Vigilância sanitária de Alimentos - DINAL. Padrões microbiológicos para produtos expostos à venda ou de alguma forma destinados ao consumo. Portaria n. ${ }^{\circ} 451$ de 19 de setembro de 1997. Diário Oficial da União, Brasília, 22 de setembro de 1997. Seção I, p.21005-21012.

CHALKER, R.B., BLASER, M.J. A review of human salmonellosis: III magnitude of Salmonella infection in the United States. Rev Infect Dis, v.10, n.1, p.111-124, 1988.

D'AOUST, J.Y., SEWELL, A., JEAN, A. Limited sensitivity of short (6h) selective enrichment for detection of foodborne Salmonella. J Food Prot, v.53, n.7, p.562-565, 1990.

DALEY,E. Inadequacy of small transfer volume and short (6h) Selective Enrichment for the detection of foodborne Salmonella. J Food Prot, v.55, n.5, p.326-328, 1992.

GRECO, P. Detection of Salmonella in dry foods using refrigerated pre-enrichment and enrichment broth cultures: Interlaboratory study. $\mathbf{J}$ AOAC Int, v.76, n.4, p.814-821, 1993.

DUARTE, K.M.R. Anticorpos monoclonais aplicados à agricultura. Piracicaba: NAPMA, II, 1996. 48 p.

PRADO FILHO, L.G. Imunoensaios aplicados à detecção de contaminantes em alimentos. Bol SBCTA, v.32, n.1, p.64-71, 1998.

ECKNER, K.F., DUSTMAN, W.A., CURIALE, M.S., et al. Use of an elevated temperature and novobiocin in modified enzyme-linked immunoabsorbent assay for the improved recovery of Salmonella from foods. J Food Prot, v.55, n.10, p.758-762, 1992.

FANTASIA, M., FILETICI, E. Salmonella enteritidis in Italy. Int J Food Microbiol, v.21, n.1, p.7-13, 1994.

FUZIHARA, T.O., FRANCO, B. D. G. M. Bactérias patogênicas e bactérias indicadoras de higiene em carne suína comercializada em Santo André - São Paulo. Cienc Tec Aliment, v.13, n.1, p.77-88, 1993. 
HAJDENWURCEL, J.R. Atlas de microbiologia de alimentos. São Paulo : Higiene Alimentar, 1997. 96 p.

HANAI, K., SATAKE, M., NAKANISHI, H., et al. Comparison of commercially available kits with standard methods for detection of Salmonella strains in foods. Appl Environ Microbiol, v.63, n.2, p.775-778, 1997.

HARLOW, E., LANE, D. Antibodies: a laboratory manual. 2.ed. New York : Cold Spring Harbor Laboratory, 1988. 453 $\mathrm{p}$

JAY, L.S., COMAR, D. Comparative study of TECRA ${ }^{\circledR}$ Salmonella Visual Immunoassay and Australian Standard cultural methods for analysis of salmonellaes in foods. Food Technol Austr, v.40, n.5, p.186-191, 1988

LAZARO, N.S., TIBANA, A., HOFER, E. Salmonella spp. in healthy swine and in abattoir environments in Brazil. J Food Prot, v.60, n.9, p.1029-1033, 1997.

McDONOUGH. P.L., JACOBSON, R.H., TIMONEY, J.F., et al Interpretations of antibody responses to Salmonella enterica serotype Enteritidis gm flagellin in poultry flocks are enhanced by a kinectics-based enzyme-linked immunoabsorbent assay. Clin Diag Lab Immunol, v.5, n.4, p.550-555, 1998.

NOGUEIRA PINTO, J.P.A., CASTRO, A.P., OHASHI, F.H., $\boldsymbol{e}$ al. Avaliação microbiológica de produtos embutidos encaminhados ao serviço de orientação à alimentação pública (SOAP) da FMVZ, UNESP, Campus de Botucatu. In: CONGRESSO BRASILEIRO DE HIGIENISTAS DE ALIMENTOS, 5, 1999, Foz do Iguaçu. Anais... São Paulo : Rev. Higiene Alimentar, 1999. V.13, n.61, p.69.

OMS (ORGANIZAÇÃO MUNDIAL DA SAÚDE). Multiresistant Salmonella typhimurum DT 104, Czech
Republic. Wkly Epidemiol Rec, v.73, n.49, p.385-386, 1998

REIS, R.B., KRUGER, C.S., MACIEL, M.S. Salmonella spp. em produtos cárneos comercializados no município de Cuiabá- MT. Avaliação da metodologia de pesquisa. Modelos de resistência a drogas antimicrobianas. Cienc Tec Aliment, v.15, n.1, p.74-78, 1995.

FRANCO, B.D.G.M., MAMIZUKA, E.M Padronização de um teste imunoenzimático para detecção de Salmonella em alimentos. In: SIMPÓSIO LATINOAMERICANO DE CIÊNCIA DE ALIMENTOS, 3, 1999, Campinas. Anais... Campinas, SP: Sociedade Brasileira de Ciência e Tecnologia de Alimentos - UNICAMP, 1999. p.86.

SABIONI, J.G., MAIA, A.R.P., LEAL, J.A. Avaliação microbiológica de lingüiça frescal comercializada na cidade de Ouro preto, MG. Hig Alimentar, v.13, n.61, p.110-113, 1999.

SIMONE, E., GOOSEN, M., NOTERMANS, S.H.W., $\boldsymbol{e}$ t al Investigations of foodborne diseases by Food Inspection Services in the Netherlands, 1991 to 1994. J Food Prot, v.60, n.4, p.442-446, 1997.

TAPCHAISRI, P., WANGROONGSARB, P., PANBANGRED, W., et al. Detection of Salmonella contamination in food samples by dot-ELISA, DNA amplification and bacterial culture. Asian Pac J Allergy Immunol, v.17, n.1, p.41-51, 1999.

THORNS, C.J., BELL, M.M., SOJKA, M.G., et al. Development and application of enzyme-linked immunoabsorbent assay for detection of Salmonella enteritidis infections in chickens based on antibodies to SEF14 fimbrial antigen. J Clin Microbiol, v.34, n.4, p.792-797, 1996. 